Relations industrielles

Industrial Relations

\title{
Les vacances payées au Canada
}

Volume 13, numéro 1, janvier 1958

URI : https://id.erudit.org/iderudit/1022474ar

DOI : https://doi.org/10.7202/1022474ar

Aller au sommaire du numéro

Éditeur(s)

Département des relations industrielles de l’Université Laval

\section{ISSN}

0034-379X (imprimé)

1703-8138 (numérique)

Découvrir la revue

Citer ce document

(1958). Les vacances payées au Canada. Relations industrielles / Industrial

Relations, 13(1), 103-103. https://doi.org/10.7202/1022474ar

Tous droits réservés (C Département des relations industrielles de l’Université Laval, 1958
Ce document est protégé par la loi sur le droit d'auteur. L’utilisation des services d'Érudit (y compris la reproduction) est assujettie à sa politique d'utilisation que vous pouvez consulter en ligne.

https://apropos.erudit.org/fr/usagers/politique-dutilisation/ 


\section{LES VACANCES PAYEES AU CANADA}

Les vacances payées des travailleurs canadiens sont plus répandues et plus longues et exigent une période d'admissibilité relativement plus courte que jamais, selon les renseignements publiés le ler actobre 1957 par le ministre fédéral du Travail, l'hon. Michael Starr.

Ces renseignements ressortent du relevé annuel (1956) des conditions de travail effectué par la Division de l'économique et de recherches du ministère du Travail. Le relevé a porté sur des établissements de la plupart des industries, lesquels occupaient collectivement $1,600,000$ travailleurs. De ce nombre, 75 p. 100 environ étaient des travailleurs d'usine et les autres des employés de bureau.

(On trouvera de plus amples détails dans le numéro de septembre 1957 de la Gazette du Travail.)

Les changements les plus notables quant aux pratiques en matière de vacances au Canada ont été, d'abord, la hausse de leur incidence, particulièrement dans le cas des travailleurs d'usine; deuxièmement, le prolongement des vacances annuelles de deux à trois semaines par année, en certains cas à quatre; et troisièmement, la réduction des exigences de service pour l'admissibilité à des vacances de diverses durées. Une autre caractéristique est la similitude croissante, dans la plupart des groupes industriels, entre les vacances des travailleurs d'usine et celle des employés de bureau.

En 1949, 97 p. 100 des employés de bureau de l'industrie manufacturière jouissaient de vacances payées de deux semaines comparativement à $81 \mathrm{p}$. 100 des travailleurs d'usine. En 1956 les pourcentages correspondants étaient de 99 et 92 p. 100. De même, en 1949, 42 p. 100 des employés de bureau pouvaient acquérir le droit à des vacances de trois semaines, en comparaison de seulement 30 p. 100 des travailleurs d'usine, tandis qu'en 1956 ces chiffres s'établissaient à 72 et 63 p. 100 respectivement. Dans tous les cas, les vacances étaient sujettes à des périodes de service variant quant à la durée.

Le tableau ci-après donne le pourcentage des employés dans les établissements signalant des vacances de 2,3 et 4 semaines. Il montre la similitude actuelle dans les vacances des employés de bureau et des travailleurs d'usine.

Bureau Usine

Industrie manufacturière

Mines de charbon

Mines de métaux

Chemins de fer à vapeur

Transport en commun (urbain et suburbain)

Camionnage

Services d'utilités publiques

Commerce de gros

Commerce de détail

Buanderies

Hôtels

Restaurants

99
98
97
99
99
82
94
81

2 semaines

$\% \%$

3 semaines

Bureau Usine

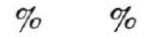

$\begin{array}{cc}63 & 72 \\ \mathrm{v} & \mathrm{v} \\ 48 & 56 \\ 100 & 100\end{array}$

100

$\begin{array}{rr}92 & 99 \\ 99 & 99 \\ 91 & 91 \\ 100 & 100\end{array}$

\section{9}

95

94

96

98

65

93

72

\section{8}

97

99

82

94

81
4 semaines

Bureau Usine

$\% \quad \%$

\section{0}

13

$\mathrm{v} \quad \mathrm{v}$

$25 \quad 40$

V v

v Moins de 1 p. 100

Il est à noter dans le tableau ci-dessus qu'en général la proportion d'employés de bureau est plus élevée que celle des travailleurs d'usine, bien que la colonne «3 semaines» montre quelques exemples du contraire. 